\title{
ANÁLISE DO COMÉRCIO DE BANANAS EM LAVRAS - MINAS GERAIS
}

\author{
Analysis of banana trade in Lavras - Minas Gerais \\ Lair Victor Pereira², José Clélio de Andrade³, José Carlos Fráguas', \\ Enilson Abrahão ${ }^{5}$, Ângelo Albérico Alvarenga ${ }^{6}$
}

\begin{abstract}
RESUMO
A participação de Lavras na oferta de banana no mercado local é muito pequena, considerando-se que o Brasil é o segundo país maior produtor com 6,6 milhões de toneladas e Minas Gerais é o quarto entre os Estados produtores dessa fruta. Visando a quantificar a participação de Lavras e região na oferta de banana no mercado local, realizou-se esse trabalho em duas etapas: 2002/2003 e 2004/ 2005. A aplicação mensal de questionários nos principais estabelecimentos comerciais de hortifruti e feiras - livre de Lavras, permitiu conhecer o volume comercializado, procedência e perdas das principais cultivares de banana. Os resultados obtidos mostram que em $2002 / 2003$ foram comercializados 945,24 te em 2004/2005 foi de 1.001,98 t. Desse volume, 6,56\% em 2002/2003 e 14,62\% em 2004/ 2005 tiveram como origem Lavras. O consumo per capita anual manteve-se em torno de 11,8 kg nos dois períodos pesquisados. As bananas tipo 'Prata', foram as mais comercializadas nas duas etapas, $54,7 \%$ no primeiro período e $58,7 \%$ no segundo, sendo que $7,91 \%$ e 18,35\% , respectivamente, tiveram como origem Lavras. O volume de banana 'Marmelo' e do tipo 'Nanicão', foram de 1,91\% e 28,4\%, respectivamente, sendo que 84,0\% da 'Marmelo' e 3,43\% da tipo 'Nanicão' na segunda etapa foram procedentes de Lavras. A banana 'Maçã' teve uma redução de 125,30 t para 107,47 t, correspondendo a 13,26\%, sendo que a oferta dessa cultivar, originada de Lavras, manteve-se em 13,8\%. As bananas 'Maçã' e 'Marmelo' apresentaram as menores perdas, 3,56\% e 4,78\% e as dos tipos 'Prata'e 'Nanicão' as maiores perdas, 9,39\% e 10, 75\%, respectivamente.
\end{abstract}

Termos para indexação: Comercialização, procedência, perdas, Musa spp.

\section{ABSTRACT}

The participation of Lavras in the banana production offered to the local commerce is still very low considering that Brazil is the second banana producer of the world, with a production around 6.6 ton/year and per-capita consumption of $24.4 \mathrm{~kg} / \mathrm{year}$. Minas Gerais ranks in the fifth place among the most important Brazilian state producers. This research was carried out between 2002/2003 and 2004/2005, aimed to quantify Lavras participation in the banana market in the period considered. Monthly, a questionnaire was applied in the main produce commercial centers in Lavras, in order to assess the commercialized amount and the origins and losses of banana of the main cultivars during their commercialization chain. The results show that in 2002/2003, 945.24 ton was commercialized while this value reached 1,001.98 ton in 2004/2005. From this volume, $6.56 \%$ in the first phase and $14.6 \%$ in the second phase had the origin in Lavras. A 6\% increase was verified from the first to the second phase. The per capita consumption was kept around $11.8 \mathrm{~kg} /$ year. The 'Prata' banana was the most commercialized in Lavras, representing $54.7 \%$ and $58.7 \%$, in the first and second phase, respectively. In the first phase, $7.9 \%$ was from Lavras region and $18.3 \%$, in the second phase. The amounts of 'Marmelo' banana and of 'Nanicão'-like were $1.91 \%$ and $28.40 \%$, respectively. The 'Marmelo' banana produced in Lavras was kept around $84.00 \%$ in both phases, while the 'Nanicão'-like was $84.0 \%$ and $3.43 \%$ in the first and second phase, respectively. The 'Maçã' banana had a reduction of 125.30 to 107.47 ton correspondent to $13.26 \%$ and the participation of Lavras in its production was around $13.8 \%$. The 'Maçã' and 'Marmelo' bananas presented the lowest losses, $3.56 \%$ and $4.78 \%$, whereas those like 'Prata' and 'Nanicão' showed the highest losses, $9.39 \%$ and $10.75 \%$, respectively.

Index terms: Commercialization, origin, losses, Musa spp.

\section{(Recebido em 22 de setembro de 2006 e aprovado em 7 de março de 2008)}

\section{INTRODUÇÃO}

Apesar de estar o Brasil entre os três países maiores produtores de frutas do mundo sua participação na exportação é de apenas 3,0 \% (AGRIANUAL, 2007) e o seu consumo per capita anual é muito baixo $57,0 \mathrm{~kg}$, quando comparado com o de outros países como a Itália com $114 \mathrm{~kg}$ e Espanha com $120 \mathrm{~kg}$ (FRUTICULTURA, 2004).

\footnotetext{
'Trabalho patrocinado e financiado pela EPAMIG/CTSM

Engenheiro Agrônomo, Mestre em Fitopatologia, Pesquisador - Centro Tecnológico do Sul de Minas/CTSM - Empresa de Pesquisa Agropecuária de Minas Gerais/EPAMIG - Campus UFLA - Cx. P. 176 - 37200-000 - Lavras, MG - lair@epamig.br ${ }^{3}$ Engenheiro Agrônomo, Mestre em Administração, Pesquisador - Centro Tecnológico do Sul de Minas/CTSM - Empresa de Pesquisa Agropecuária de Minas Gerais/EPAMIG - Campus UFLA - Cx. P. 176 - 37200-000 - Lavras, MG - jclelio@epamig.br

${ }^{4}$ Engenheiro Agrônomo, Doutor, Pesquisador - Centro Tecnológico do Sul de Minas/CTSM - Empresa de Pesquisa Agropecuária de Minas Gerais/EPAMIG Campus UFLA - Cx. P. 176 - 37200-000 - Lavras, MG - fraguas@epamig.ufla.br

${ }^{5}$ Engenheiro Agrônomo, Mestre em Fitotecnia, Pesquisador - Centro Tecnológico do Sul de Minas/CTSM - Empresa de Pesquisa Agropecuária de Minas Gerais/EPAMIG - Campus UFLA - Cx. P. 176 - 37200-000 - Lavras, MG - enilson@epamig.ufla.br

${ }^{6}$ Engenheiro Agrônomo, Doutor em Fitotecnia, Pesquisador - Centro Tecnológico do Sul de Minas/CTSM - Empresa de Pesquisa Agropecuária de Minas Gerais/EPAMIG - Campus UFLA - Cx. P. 176 - 37200-000 - Lavras, MG - angelo@epamig.ufla.br
} 
Dentre as frutas mais consumidas no mundo, segundo Souza (2004) a banana é a de maior consumo per capita $(11,2 \mathrm{~kg})$ seguida da laranja $(11,0 \mathrm{~kg})$, da maçã $(8,2$ $\mathrm{kg})$ e da uva $(3,1 \mathrm{~kg})$.

A banana ocupa o segundo lugar dentre as frutíferas mais exploradas no Brasil (MASCARENHAS, 1999; SOUZA \& TORRES FILHO, 1999). Segundo Agrianual (2007) e IBGE (2007) o Brasil produziu em $2006 \mathrm{em}$ torno de 6,99 milhões de $t$ de bananas em uma área de 505,384 ha com um rendimento de 13,81 t/ha/ano.

Quanto à produção de banana por estados do Brasil, segundo o Agrianual (2007), Minas Gerais em 2004 e 2005 manteve-se em quarto lugar dentre os maiores produtores. Todavia, em 2006, houve uma queda na produção $(506,334$ t) e na área plantada (37.043 ha) passando então para o quinto lugar, mas o rendimento manteve-se em torno de 14,65 t/ha/ano. Por outro lado, segundo o IBGE (2007), em 2006 Minas Gerais, com uma produção de 554,039 t e um rendimento em torno de 14,7 t/ha/ano, é o quarto Estado maior produtor de banana do Brasil.

Com relação à procedência da banana comercializada na CEASA-MG, em $1999,57,1 \%$ foi de bananas tipo 'Prata', 37,3\% do tipo 'Caturra' ou 'Nanicão' e 3,6\% de banana 'Maçã' (BRASIL, 2000). Ainda, 95,2\% de bananas tipo 'Prata', 60,8\% das do tipo 'Nanicão' e 35,3\% de bananas 'Maçã' comercializadas na CEASA-MG, foram produzidas em Minas Gerais.

Segundo Cançado Júnior et al. (1999), a região sul de Minas Gerais possui uma área plantada de 10.800 ha, com uma produção média de 850 cachos/ha. Esse baixo índice de rendimento é atribuído ao nível tecnológico, a cultivar plantada, que é de porte alto, requerendo maior espaçamento e, conseqüentemente, menor densidade de plantio. Nessa região, os municípios maiores produtores são Brazópolis, com cerca de 1.400 ha e Pedralva com 600 ha, com uma produtividade média de 9,0 t/ha/ano (BRASIL, 2000).

Em relação ao mercado de frutas em Lavras - MG, Santos \& Silva (1998) relatam que do total de bananas comercializadas em 1997, 67,5\% foram do tipo 'Prata', 24,5\% das variedades do tipo 'Nanicão', 16,8\% de banana 'Maçã̃' e $1,2 \%$ de banana do subgrupo Terra. Segundo esses autores, desse total, apenas $20 \%$ das bananas do tipo 'Prata' e $21 \%$ 'Maçã̃', tiveram como origem a região de Lavras, sendo o restante, procedente da CEASA-MG (85\%) e da CEAGESP (15\%).

Segundo Pereira et al. (2006), levantamento realizado em Lavras nos períodos 2002/2003 e 2004/2005, indica que foram comercializadas mensalmente 78,77 e 83,49 $\mathrm{t}$ de banana, respectivamente.
De acordo com Souza \& Torres Filho (1999), no Brasil, as perdas pós-colheita que ocorrem nas fases de distribuição, armazenamento e comercialização são estimadas em $30 \%$.

Com relação ao consumo per capita anual de banana segundo Mascarenhas (1999), o consumo per capita anual aparente foi de $24,11 \mathrm{~kg}$ no triênio $1995 / 97$, sem incluir perdas de 40\%, enquanto Fancelli (2003) relata um consumo per capta em torno de $25 \mathrm{~kg} / \mathrm{ano}$. Por outro lado, os dados da Pesquisa de Orçamentos Familiares (POFs) referente ao consumo familiar de banana em onze regiões metropolitanas do Brasil mostram um consumo per capita anual de 10,7 kg em 1987/88 e de 7,9 kg em 1997 (IBGE, 1997). Pesquisa no mercado varejista de banana em Lavras realizada no período de 2002 a 2005 apontou um consumo per capita de 11,81 kg/ano (PEREIRA et al., 2008).

Neste trabalho, objetivou-se identificar o volume comercializado, procedência e índice de perdas de banana no mercado varejista de Lavras - MG.

\section{MATERIAL E MÉTODOS}

Essa pesquisa foi realizada mensalmente, em duas etapas, sendo a primeira no período de julho de 2002 a junho de 2003 e a segunda no período de julho de 2004 a junho de 2005.

A metodologia empregada foi a aplicação de um questionário com as seguintes perguntas: quantidade comercializada de banana de cada cultivar, sua procedência e perdas. No que se refere à procedência considerou-se como origem as bananas provenientes das CEASA-MG, CEAGESP, de Lavras e região. Com relação a Lavras e região considerou-se a banana produzida nos municípios de Lavras, Nepomuceno, Perdões, Campo Belo e outros municípios vizinhos.

A pesquisa foi realizada em quinze estabelecimentos varejistas de hortifruti e duas feiras - livre da cidade de Lavras na primeira etapa e, na segunda etapa foram incluídos mais três novos estabelecimentos.

Considerando-se os estabelecimentos pesquisados nas duas etapas, estimou-se que eles movimentam cerca de $95 \%$ de toda a banana comercializada em Lavras.

\section{RESULTADOS E DISCUSSÃO}

De acordo com os dados da Tabela 1, observa-se que o volume total e médio mensal de bananas comercializadas em Lavras tiveram um aumento médio de 6,0 \%, passando de um total anual de 945,24 t e uma média de $78,77 \mathrm{t} / \mathrm{mês}$ na primeira etapa, para 1.001,98 t e uma média de 83,50 t/mês na segunda etapa. 
Esse aumento de $6,0 \%$ no volume de bananas comercializado em Lavras deveu-se a inclusão de mais três estabelecimentos varejistas de hortifruti e ao aumento populacional da cidade no período de 2002 a 2005.

A participação de Lavras e região na oferta de banana teve um expressivo incremento $(22,86 \%)$ da primeira para a segunda etapa. Esse incremento é atribuído muito mais ao aumento de área da área plantada, principalmente com as cultivares dos tipos Prata e 'Nanicão' e outras cultivares como Marmelo e Prata Graúda do que ao do consumo per capta que passou de 11,81 para $11,96 \mathrm{~kg} / \mathrm{ano}$ da primeira para a segunda etapa.

O consumo per capita de banana em Lavras, 11,81 kg/ano em 2002/2003 e 11,96 kg/ano em 2004/2005 foi ligeiramente superior ao do Brasil (11,2 kg/ano) relatado por Souza (2004) é bastante superior àquele encontrado pela Pesquisa de Orçamentos Familiares (POF), 9,7 kg/ano em 1996. Esses valores são bastante inferiores àqueles relatados por Fancelli (2003) 25,0 kg/ano. Essa discrepância se deve basicamente ao fato desses consumos per capta ser calculado com base na quantidade produzida dividida pela população sem considerar perdas na colheita, póscolheita e comercialização. Tais perdas chegam a atingir valores superiores a $40 \%$ conforme relatam Mascarenhas (1999) e Souza \& Torres (1999).
Com relação ao volume de bananas por cultivar comercializado em Lavras (Tabela 2), observa-se que aquelas do tipo 'Prata' foram as únicas que tiveram aumento no volume, passando de 516,92 t em 2002/2003 para 588,16 t em 2004/2005, incremento de 13,78\%. Esse aumento foi maior de outubro a maio nas duas etapas. As bananas 'Marmelo' e as do tipo 'Nanicão' tiveram um pequeno aumento da primeira para a segunda etapa, ou seja, $4,72 \%$ e $3,48 \%$, respectivamente.

Essa redução do volume de banana 'Prata' comercializada em Lavras, pode ser atribuída à diminuição da área plantada em conseqüência da dizimação dos bananais pelo Mal do Panamá e o desinteresse dos produtores em plantar novas áreas com essa cultivar em razão dos riscos com essa doença. Essa redução da oferta de banana 'Maçã' forçou a elevação do seu preço em torno de $20 \%$

Com relação a outras cultivares (Terra, Ouro, Prata Graúda, Mysore e Leite) a redução do volume comercializado foi conseqüência provavelmente da não preferência pelos consumidores, principalmente pelas cultivares Terra e Ouro, todas procedentes da CEASAMG e CEAGESP e oferta de outras cultivares, como a Prata Graúda, produzidas em Lavras, porém com pequena oferta.

Tabela 1 - Procedência da banana comercializada em Lavras - MG no período de 2002 a 2005

\begin{tabular}{|c|c|c|c|c|c|c|}
\hline \multicolumn{7}{|c|}{ Quantidade $(\mathrm{t})$ por etapa e procedência } \\
\hline \multirow[b]{2}{*}{ Meses } & \multicolumn{3}{|c|}{$1^{\mathrm{a}}$ etapa $(2002 / 2003)$} & \multicolumn{3}{|c|}{$2^{a}$ etapa $(2004 / 2005)$} \\
\hline & $\begin{array}{c}\text { CEASA's } \\
(\mathrm{MG} / \mathrm{SP})\end{array}$ & $\begin{array}{l}\text { Lavras e } \\
\text { região }\end{array}$ & Total & $\begin{array}{c}\text { CEASA's } \\
(\mathrm{MG} / \mathrm{SP})\end{array}$ & $\begin{array}{c}\text { Lavras e } \\
\text { região }\end{array}$ & Total \\
\hline Julho & 68,84 & 4,16 & 73,00 & 69,10 & 9,74 & 78,84 \\
\hline Agosto & 68,34 & 4,38 & 72,72 & 67,72 & 9,90 & 77,62 \\
\hline Setembro & 68,66 & 5,78 & 74,44 & 71,16 & 9,62 & 80,78 \\
\hline Outubro & 71,70 & 7,08 & 78,78 & 71,66 & 12,06 & 83,72 \\
\hline Novembro & 72,26 & 7,28 & 83,54 & 70,46 & 14,64 & 85,10 \\
\hline Dezembro & 78,28 & 5,72 & 84,00 & 75,80 & 13,08 & 88,56 \\
\hline Janeiro & 76,68 & 4,96 & 81,64 & 77,12 & 13,46 & 90,58 \\
\hline Fevereiro & 78,58 & 5,02 & 83,60 & 75,96 & 13,06 & 89,02 \\
\hline Março & 77,04 & 4,04 & 81,08 & 73,46 & 12,82 & 86,28 \\
\hline Abril & 75,04 & 4,20 & 79,24 & 69,36 & 12,94 & 82,30 \\
\hline Maio & 72,12 & 4,48 & 77,60 & 68,40 & 13,70 & 82,10 \\
\hline Junho & 70,74 & 4,86 & 75,60 & 65,48 & 11,52 & 77,00 \\
\hline TOTAL & 882,28 & 61,96 & 945,24 & 855,36 & 146,54 & $1.001,98$ \\
\hline Média/mês & 73,51 & 5,16 & 78,77 & 71,20 & 12,21 & 83,49 \\
\hline$\%$ Anual & 93,44 & 6,56 & 100,00 & 85,37 & 14,62 & 100,00 \\
\hline Consumo per capita & ----- & ----- & 11,81 & ----- & ----- & 11,96 \\
\hline
\end{tabular}




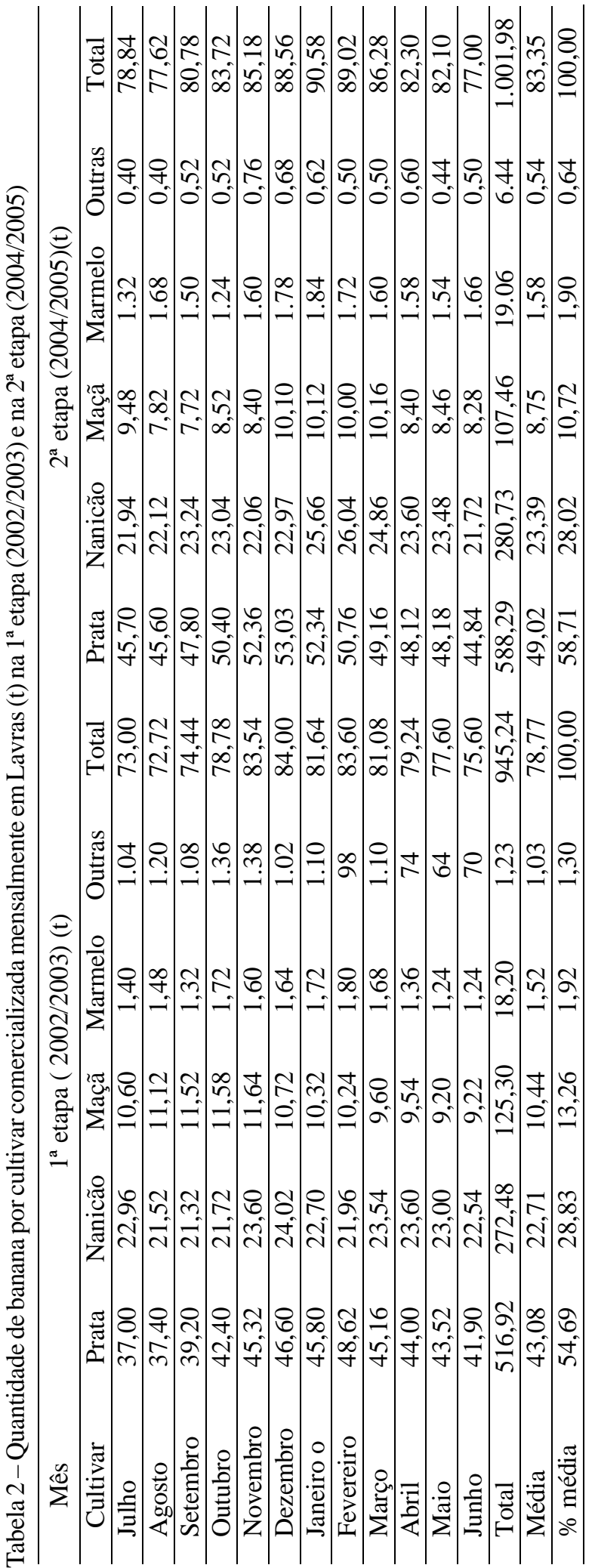

O incremento de 13,78\% no volume de banana tipo 'Prata', da primeira para a segunda etapa, pode ser atribuído ao crescimento da população de Lavras e pela maior preferência por esta cultivar e à redução da oferta de banana 'Maçã'.

Analisando os volumes de bananas por cultivar comercializados em Lavras, observa-se que a participação da banana tipo 'Prata' passou de 54,69\% para 58,70\% na segunda etapa, enquanto que a cultivar Marmelo e as do tipo Nanicão se mantiveram em torno de $28,8 \%$ e 1,9\%, respectivamente. Por outro lado, a banana 'Maçã' apresentou uma queda de 13,26\% para 10,72 \% na sua participação.

Comparando esses resultados com aqueles relatados por Santos \& Silva (1998), pode-se observar que, para as bananas do tipos 'Prata' e 'Nanicão', não houve grande diferença quanto às suas participações em relação às demais cultivares. Por outro lado, para a banana 'Maçã' observa-se uma significativa tendência de redução na sua participação, sendo que em 1998 era de 21,0\% (SANTOS \& SILVA, 1998), em 2002/2003 de 13,26\% e em 2004/2005 de 10,72\% (PEREIRA et al., 2008).

Com relação à procedência das cultivares de banana comercializada em Lavras, Tabela 3, observa-se que para as bananas do tipo 'Prata', 7,91\% em 2002/2003 e $18,35 \%$ em 2004/2005, tiveram como origem Lavras e região. Esse incremento pode ser atribuído à expansão da área plantada e ao aumento do número de produtores dessas cultivares, principalmente da 'Prata Anã'. Apesar da tendência de aumento do volume das bananas tipo Prata ofertadas por Lavras e região nos períodos estudados (13,78\%) , esses valores ainda estão abaixo daquele relatado por Santos \& Silva (1998) que foi de 20,0\%.

Quanto à procedência das bananas tipo 'Nanicão' comercializadas em Lavras tanto em 2002/2003 como em 1998, tiveram como origem as CEASA-MG e CEAGESP. Entretanto, em 2004/2005, 9,64 t, ou seja 3,48\% do volume total desse tipo de banana tiveram como origem Lavras e região. Isto demonstra o interesse de alguns produtores em diversificar sua produção introduzindo novas cultivares.

A banana 'Maçã' apresentou significativa redução de volume comercializado da primeira para a segunda etapa, tanto nas procedentes das CEASA-MG e CEAGESP, de 107,54 t para 92,87 t (13,64\%) como nas produzidas em Lavras e região, de 17,46 t para 14,64 t (16,15\%).

Quanto à procedência da banana 'Marmelo' comercializada em Lavras, observa-se um pequeno aumento de 5,38\% no volume comercializado e de 3,15\% na participação de Lavras. Nos meses de outubro a março, 
houve uma maior oferta dessa cultivar pelo município de Lavras nas duas etapas estudadas. Contudo, não é possível estabelecer comparações do volume comercializado e procedência dessa cultivar pois, Santos \& Silva (1998) não fazem nenhuma referência à banana 'Marmelo'.

Com relação às perdas no comércio varejista de bananas em Lavras, no período de 2002 a 2005 (Tabela 4), observa-se que as cultivares dos tipos Prata e Nanicão apresentaram os maiores índices, 9,39\% e 10,75\%, respectivamente. Por outro lado, a banana 'Maçã' apresentou o menor índice (3,56\%) seguida da 'Marmelo' $(4,78 \%)$. Observa-se ainda, que independentemente da cultivar, as maiores perdas ocorreram nos meses de dezembro, janeiro e fevereiro, período mais quente do ano, uma vez que o calor reduz o período de conservação das frutas expostas em ambientes sem controle de temperatura. As perdas detectadas no mercado varejista de Lavras são decorrentes de danos durante a colheita,

Tabela 3 - Quantidade de bananas comercializadas em Lavras - MG por etapas, cultivar e procedências

\begin{tabular}{|c|c|c|c|c|c|c|c|c|c|}
\hline \multirow{4}{*}{ Cultivar } & \multicolumn{9}{|c|}{ Quantidade, etapas e procedências } \\
\hline & \multicolumn{5}{|c|}{$1^{\text {a }}$ etapa $(2002 / 2003)$} & \multicolumn{4}{|c|}{$2^{a}$ etapa $(2004 / 2005)$} \\
\hline & & \multicolumn{2}{|c|}{ Ceasas (MG e SP) } & \multicolumn{2}{|c|}{ Lavras e região } & \multicolumn{2}{|c|}{ Ceasas (MG e SP) } & \multicolumn{2}{|c|}{ Lavras e região } \\
\hline & & $(\mathrm{t})$ & $(\%)$ & $(\mathrm{t})$ & $(\%)$ & $(\mathrm{t})$ & $(\%)$ & $(\mathrm{t})$ & $(\%)$ \\
\hline \multirow[b]{2}{*}{ Prata } & Total/ano & 476,35 & 92,09 & 40,64 & 7,91 & 480,40 & 81,65 & 107,76 & 18,35 \\
\hline & $\begin{array}{l}\text { Média } \\
\text { mensal }\end{array}$ & 39,70 & --- & 3,39 & --- & 40,03 & --- & 8,96 & --- \\
\hline \multirow[b]{2}{*}{ Nanicão } & Total/ano & 272,46 & 100,00 & 0,00 & 0,00 & 271,08 & 96,57 & 9,64 & 3,43 \\
\hline & $\begin{array}{l}\text { Média } \\
\text { mensal }\end{array}$ & 22,71 & --- & --- & --- & 22,59 & --- & 0,80 & --- \\
\hline \multirow[b]{2}{*}{ Maçã } & Total/ano & 107,54 & 86,03 & 17,46 & 13,97 & 92,87 & 86,38 & 14,64 & 13,62 \\
\hline & $\begin{array}{l}\text { Média } \\
\text { mensal }\end{array}$ & 8,96 & --- & 1,45 & --- & 7,74 & --- & 1,22 & --- \\
\hline \multirow[b]{2}{*}{ Marmelo } & Total/ano & 3,02 & 16,57 & 15,20 & 83,43 & 3,52 & 17,73 & 15,68 & 82,27 \\
\hline & $\begin{array}{l}\text { Média } \\
\text { mensal }\end{array}$ & 0,25 & --- & 1,27 & --- & 0,27 & --- & 1,31 & --- \\
\hline \multirow{2}{*}{$\begin{array}{l}\text { Outras } \\
\text { cultivares }\end{array}$} & Total/ano & 12,12 & 97,97 & 0,25 & 2,03 & 5,85 & 90,27 & 0,63 & 9,73 \\
\hline & $\begin{array}{l}\text { Média } \\
\text { mensal }\end{array}$ & 1,01 & --- & 0,02 & --- & 0,49 & --- & 0,05 & --- \\
\hline
\end{tabular}

Tabela 4 - Valores médios em porcentagem de perdas no varejo de bananas por cultivares comercializadas em Lavras MG nos períodos de 2002/2003 a 2004/2005

\begin{tabular}{|c|c|c|c|c|c|c|}
\hline \multicolumn{7}{|c|}{ Porcentagem de perda por cultivar } \\
\hline Meses & Prata & Nanicão & Maçã & Marmelo & $\begin{array}{c}\text { Outras } \\
\text { cultivares }\end{array}$ & Média \\
\hline Julho & 8,30 & 10,00 & 3,30 & 4,20 & 6,70 & 6,50 \\
\hline Agosto & 8,50 & 10,20 & 3,60 & 4,65 & 6,95 & 6,78 \\
\hline Setembro & 8,50 & 10,50 & 3,80 & 4,50 & 7,10 & 6,88 \\
\hline Outubro & 8,70 & 10,50 & 3,90 & 4,70 & 7,20 & 7,00 \\
\hline Novembro & 9,50 & 11,00 & 3,80 & 4,90 & 7,57 & 7,31 \\
\hline Dezembro & 11,60 & 12,20 & 4,00 & 5,40 & 8,57 & 8,35 \\
\hline Janeiro & 11,00 & 12,50 & 4,10 & 5,50 & 8,30 & 8,28 \\
\hline Fevereiro & 10,80 & 11,30 & 3,80 & 5,30 & 8,05 & 7,85 \\
\hline Março & 9,60 & 10,60 & 3,60 & 5,00 & 7,45 & 7,23 \\
\hline Abril & 9,20 & 10,40 & 3,20 & 4,60 & 7,10 & 6,90 \\
\hline Maio & 8,50 & 10,30 & 2,80 & 4,35 & 6,75 & 6,54 \\
\hline Junho & 9,40 & 10,20 & 2,70 & 4,16 & 6,60 & 6,41 \\
\hline Média & 9,39 & 10,75 & 3,56 & 4,78 & 7,38 & 7,17 \\
\hline
\end{tabular}


Tabela 4 - Valores médios em porcentagem de perdas no varejo de bananas por cultivares comercializadas em Lavras MG nos períodos de 2002/2003 a 2004/2005

\begin{tabular}{|c|c|c|c|c|c|c|}
\hline \multicolumn{7}{|c|}{ Porcentagem de perda por cultivar } \\
\hline Meses & Prata & Nanicão & Maçã & Marmelo & $\begin{array}{c}\text { Outras } \\
\text { cultivares }\end{array}$ & Média \\
\hline Julho & 8,30 & 10,00 & 3,30 & 4,20 & 6,70 & 6,50 \\
\hline Agosto & 8,50 & 10,20 & 3,60 & 4,65 & 6,95 & 6,78 \\
\hline Setembro & 8,50 & 10,50 & 3,80 & 4,50 & 7,10 & 6,88 \\
\hline Outubro & 8,70 & 10,50 & 3,90 & 4,70 & 7,20 & 7,00 \\
\hline Novembro & 9,50 & 11,00 & 3,80 & 4,90 & 7,57 & 7,31 \\
\hline Dezembro & 11,60 & 12,20 & 4,00 & 5,40 & 8,57 & 8,35 \\
\hline Janeiro & 11,00 & 12,50 & 4,10 & 5,50 & 8,30 & 8,28 \\
\hline Fevereiro & 10,80 & 11,30 & 3,80 & 5,30 & 8,05 & 7,85 \\
\hline Março & 9,60 & 10,60 & 3,60 & 5,00 & 7,45 & 7,23 \\
\hline Abril & 9,20 & 10,40 & 3,20 & 4,60 & 7,10 & 6,90 \\
\hline Maio & 8,50 & 10,30 & 2,80 & 4,35 & 6,75 & 6,54 \\
\hline Junho & 9,40 & 10,20 & 2,70 & 4,16 & 6,60 & 6,41 \\
\hline Média & 9,39 & 10,75 & 3,56 & 4,78 & 7,38 & 7,17 \\
\hline
\end{tabular}

aquelas relatadas por Souza \& Torres Filho (1999) e também ao manuseio inadequado e excessivo da fruta pelos vendedores e consumidores provocando, principalmente, o debulhamento das frutas conforme Lichtemberg (1999).

\section{CONCLUSÕES}

- O aumento do volume de banana comercializado em Lavras de 2002/2003 para 2004/2005 foi decorrente basicamente do crescimento populacional, uma vez que o consumo per capita manteve-se praticamente inalterado.

- A participação de Lavras na oferta de banana aumentou em $6,00 \%$ da primeira para a segunda etapa.

- $\mathrm{O}$ volume de bananas comercializado em Lavras do tipo 'Prata' teve um pequeno aumento da primeira para a segunda etapa; a 'Marmelo' e 'Nanicão' mantiveram praticamente os mesmos volumes; a 'Maçã' e outras cultivares tiveram redução nos seus volumes comercializados.

- Quanto à procedência, verificou-se que: 18,35\% da 'Prata' em 2004/2005 tiveram como origem Lavras, contra $7,91 \%$ em 2002/2003 e 3,43\% da 'Nanicão' em 2004/2005, não sendo detectada em 2002/2003.

- As bananas dos tipos 'Nanicão' e 'Prata' apresentaram os maiores índices de perdas no varejo, enquanto as bananas 'Maçã' e 'Marmelo' os menores. No período de verão, detectaram-se maiores perdas.

\section{REFERÊNCIAS BIBLIOGRÁFICAS}

AGRIANUAL. Anuário da agricultura brasileira. São Paulo: FPN Consultoria \& Comércio, 2007.

BRASIL. Ministério de Integração Nacional. Banana. Brasília, DF, 2000. 8 p. (FrutiSéries, 6).

CANÇADO JUNIOR, F. L.; ROCHA SOBRINHO, R.; MAIA, D. M. de; GERALDO, L. G. Aspectos econômicos da cultura da bananeira em Minas Gerais. Informe Agropecuário, Belo Horizonte, v. 20, n. 196, p. 5-9, 1999.

FANCELLI, M. Cultivo da banana para o estado do Amazonas. Cruz das Almas: Embrapa Mandioca e Fruticultura, 2003. 4 p. (Sistema de produção, 6).

FRUTICULTURA. Disponível em: <http:// wwww.planetaorganico.com.br/fruticultura.htm和. Acesso em: 12 maio 2004.

INSTITUTO BRASILEIRO DE GEOGRAFIA E ESTATISTICA. Produção agrícola municipal., Disponível em: <h̆ttp://www.sidra.ibge.gov.br〉. Acesso em: 21 nov. 2007.

INSTITUTO BRASILEIRO DE GEOGRAFIA E ESTATÍSTICA. Pesquisa de orçamentos familiares 1995/ 96: primeiros resultados. Rio de Janeiro, 1997. 247 p. 
LICHTEMBERG, L. A. Colheita e pós colheita da banana. Informe Agropecuário, Belo Horizonte, v. 20, n. 196, p. 73-90, 1999.

MASCARENHAS, G. C. C. Banana: comercialização e mercado. Informe Agropecuário, Belo Horizonte, v. 20, n. 196, p. 97-108, 1999.

PEREIRA, L. V.; ANDRADE, J. C.; ALVARENGA, A. A.; ABRAHÃO, E.; FRAGUAS, J. C. Análise do mercado de banana em Lavras, MG. In: II Simabana, 2008, Nova Porteirinha - MG. Simpósio Norte-mineiro sobre a cultura da banana - Simbana. Nova Porteirinha - MG: Epamig Unimontes, 2008. v. CD.
SANTOS, G. R. dos; SILVA, C. R. R. Perfil mercadológico e agronômico de bananas ofertadas no município de Lavras - MG, de acordo com a sazonalidade. Lavras: UFLA, 1998.

SOUZA, A. da S.; TORRES FILHO, P. Aspectos socioeconômicos. In: ALVES, E. J. A cultura da bananeira: aspectos técnicos, socioeconômicos e agroindustriais. 2. ed. Brasília, DF: Embrapa, 1999. cap. 17 , p. 507-543.

SOUZA, A. T. de. Aspectos econômicos da cultura da banana. Disponível em: <http://Www.ierpa.com.brh iagroindicadores/opiniao/analisebanana.htms: Ácesso em: 12 maio 2004 . 